\title{
TB in British Badgers
}

\section{Eunice D. Overend}

There is widespread concern in Britain at the Ministry of Agriculture's decision to eliminate all badgers in sets where TB has been proved. Such sets are presently only known in a few small areas in the West Country - see Oryx, October 1975, page 114. The problem concerns bovine TB, which in Britain in the 1930s was estimated to cause at least $\mathbf{2 5 0 0}$ human deaths a year (in addition to those caused by human TB), but which has now been almost eliminated with the pasteurisation of milk and the near elimination of the disease in cows by a ruthless slaughter policy. In this article the author explains why this drastic step is considered necessary and why many conservationists have regretfully agreed to support it.

Bovine TB in badgers is behaving like human 'consumption'. It can affect their lungs and, sleeping in huddles as badgers do, they can infect each other and their surroundings with the sputum they cough up. Some of this they swallow and, passing through them, it makes their dung infective. In some animals the kidneys become diseased and these will pass infective urine. As in cows, the milk may also contain the germs and so cubs may be infected from an early age. Their bite can carry the germs too, and as border fights with badgers from neighbouring groups are frequent where densities are high, these can be infected with tubercular abscesses and carry the disease further.

The body, human or animal, has natural defences against invading germs. Among these are the lymph glands scattered throughout the body which strain off and deal with invaders. Unluckily TB germs within the glands are not always killed, but they are closely confined inside tiny cysts and prevented from spreading to do further damage or infect other individuals. Here they may lie for years until a change in conditions, better for them but worse for the body they inhabit, lets them out to start a new active, infective stage of the disease. TB was one of the greatest killers in Belsen, for that reason.

If badger cubs are 'rescued' (illegally) from a threatened set which turns out to be infected, they could be carrying the germ from their mother's milk, undetected and undetectable. The diagnostic test which can find similarly infected 'reactor' cattle does not work for badgers, and if they were released in a clean area disaster might follow in a few years' time. Two which were reared this year, that looked healthy enough, turned out to be both infected and infective to those who nursed them.

Although grazing cattle could, in theory, contract infection from grass contaminated by infected dung this is not very likely, since the badger usually puts it away tidily in a little hole it digs for the purpose, under cover in a wood or hedge. However, dung is occasionally found on the surface of the ground. Cattle, too, are fastidious grazers in this respect, leaving tufts of green on and round each patch of their own dung. They are even less likely to eat the old, contaminated badger bedding, which usually comes out mixed with earth, even if they happened to find it. The most likely way in which the germ could reach them is from the sputum of an actively infected badger 
coughing and snuffling his way around a field in search of earthworms, although infection through urine cannot be ruled out.

As it is bovine TB causing the trouble the badgers must, in the first place, have caught it from cattle, though this is unlikely to have happened recently as, through regular testing, the great majority of cattle which have contracted it have been slaughtered before becoming infectious.

In the meanwhile it may have passed from badger to badger without, by chance, reaching cattle, or it may have lain dormant in the lymph glands of some long-lived individuals. It is odd, though, that it was never detected in the many dissections of badgers done for other reasons. Two possible ways in which a badger might be infected from a tuberculous cow are by eating the cleansings, as they commonly do, after she had calved, or by scratching up her dung to find the beetles underneath.

It was well known that the members of some human families were more likely to 'go down with consumption', whether or not they lived together, than those of others. This suggests a genetic basis for susceptibility and resistance. If this were also true of badgers it would account for the patchy nature of the outbreaks, as the badgers in any one area are all more or less closely related, but this would be very hard to prove.

The situation having reached this point it remains to decide what is best to do both for the farmers and their valuable cattle and the children who may drink their milk, and also for the badgers. It can do badgers no good to insist that none are killed, for the disease spreading among them is a nasty one for them, too, and a farmer who thinks his cattle are at risk will feel forced to take things into his own hands and quietly destroy them. On the other hand it can do the farmers no good to get rid of their healthy badgers. One reason is that badgers eat a large number of young rabbits, mice and voles which might otherwise grow up and take their share of the crops, but another concerns the disease itself. If badgers are disturbed by trapping and shooting at an infected set the survivors may move out, taking the disease with them. Males, in particular, can travel long distances and their journey will be made easier if the previous healthy residents have already been removed.

Although badgers are protected animals, if a set is proved by tests to be infected it is legal and sensible for the inhabitants to be destroyed. There is no ideal way, but whatever method is used it should be effective in destroying all the badgers, and it must be humane. One of the worst is undoubtedly snaring, since a badger usually steps into a snare set low enough to catch his head and is severely injured by the wire as he struggles. Live-trapping followed by shooting is one of the best ways but it takes much time to trap all the occupants of a set. The same applies to shooting by a marksman. A shotgun in unskilled hands is not a good weapon to use as the badger all too often escapes to die a lingering death from peritonitis through pellets in the abdomen.

Gassing with hydrogen cyanide, under specific licence from MAFF by qualified operators (legal since August 1st, 1975), may prove to be the best practical method. Its action is to prevent the uptake of oxygen and the heart quickly stops. Whole families, which have close social ties, die together, so there are none left grieving and there is less disturbance which may move animals out to spread the infection further.

What can we do to help in this unhappy affair? One thing is to keep as up-to-date as we can with what is happening, and to pass on what we know 
to those less well informed than ourselves who are in a position either to kill badgers or to influence policy. Another is to report by 'phone to the nearest MAFF Veterinary Investigation Centre any fresh badger casualties. These can then be collected for the deep-freeze and later checked for TB. As facilities are extended there is a great need for tests covering the whole country, to gain a wider view of the situation. Of course, the infected areas and their surroundings had to be investigated first, but these findings cannot be taken as an indication of the true position in the country as a whole. Regions free from the disease also need a careful study.

There is not enough information available on the distances badgers travel both in their normal foraging expeditions and in the larger distances covered if they move to a new area. Any specific facts about this could be passed to Dr Ernest Neal, Mansell House, Milverton, Taunton.

More accurate information on this will help the prompt eradication of the disease from infected sets while reducing the area which might have to be cleared of badgers to be 'on the safe side'.

This article is reprinted from the Dursley and Thornbury Gazette.

\section{Endangered Endemics in South Africa}

Seventeen large mammals are described as endangered, of which four are endemic and therefore endangered on a world scale, in a survey by W. von Richter of South and South West Africa's conserved areas to assess their adequacy. The results are published in Koedoe no. 17. The four endemics are the Cape and Hartmann's mountain zebras Equus z. zebra and E. z. hartmannae, bontebok Damaliscus d. dorcas, and brown hyaena Hyaena brunnea. The jackass penguin Spheniscus demersus is the only endemic of five birds described as endangered.

There is only one viable population of the Cape mountain zebra in one reserve; it could easily be attacked by disease, and a second sanctuary is urgently needed one in the Gamka Mountains has been under discussion for some time - to which the few remaining animals in the wild could be taken. The Hartmann subspecies is more numerous but very insecure, and the report recommends the expansion of the Naukluft Mountain Zebra Park, which has no permanent water, by taking in some uneconomic farming areas to make it a viable ecological unit.

Bontebok are not in immediate danger, but the outlook is not good because in the main they are being forced to subsist on inadequate grazing; where it is suitable, as in Bontebok National Park, they have to compete with other grazers, and in a few years they will outgrow the habitat. Again, more reserves are the answer.

Next to the cheetah the brown hyaena is 'probably the rarest carnivore' in South Africa, largely because every farmer's hand is against it as 'an alleged threat' to domestic stock - it can survive only in sanctuaries. In South West Africa it is believed to be near extinction.

A conservation area for the endemic jackass penguins is also considered essential; they are now concentrated on two islands, where egg collecting ('for overseas gourmets') and a reduced food supply (excessive fishing) exacerbate the threat posed by guano collection, for the sake of which the islands are not only being paved (and the penguin burrows destroyed) but also walled, a major obstacle for flightless birds trying to reach their breeding holes. A big oil spill - and there have been several in these waters - could be the final disaster. 